\title{
The Technology of Deepening Construction and Temperature Crack Control of Mass Concrete
}

\author{
Jia Hongbin ${ }^{1,}$, , Fang Guangxiu ${ }^{1, b}$ \\ ${ }^{1}$ Department of Civil Engineering, College of Engineering, Yanbian University, Yanji, 133002, China \\ a2305530073@qq.com, b1798602756@qq.com
}

Keywords: Mass Concrete, Temperature Cracks, Optimizing the Concrete Mix Design, Pouring the Concrete, Strengthening the Curing of Concrete, Testing the Temperature of the Concrete

\begin{abstract}
Temperature crack is the most difficult factor to control in mass concrete projects. It not only influences the appearance of the structure, but also affects the engineering quality and safety when seriously. So it needs to be controlled. The paper will take the HUAYI SHIHAO Holiday Hotel as an example. The project did successfully in controlling temperature cracks in mass concrete by selecting correct materials, optimizing the concrete mix design, adopting innovative technology of pouring the concrete, strengthening the curing of concrete and testing the temperature of the concrete.
\end{abstract}

\section{Introduction}

With the fast development of China's economy, plenty of high-rise buildings and buildings which are made of large span complicated structures appear promptly in the construction industry, in which mass concrete is widely used. Compared with ordinary concrete, mass concrete structure is thick, the amount of concrete pouring is large. After the completion of the concrete pouring , due to the hydration reaction of cement, a large amount of hydration heat will be produced, resulting in the increase of the internal temperature of the concrete. Concrete is such a poor conductor of heat that is not easy to distribute heat, resulting in a large temperature difference between inside and outside., when the temperature difference between inside and outside is more than 25 degrees Celsius, the cracks caused by temperature stress will be produced. The cracks can affect the beauty of buildings, reduce the durability of structures, seriously can affect the quality and safety of the building.

This paper will introduce the successful temperature crack control technology and construction experience during the construction process of the mass concrete foundation slab of HUAYI SHIHAO Holiday Hotel in Yanji City, Jilin Province. To control temperature cracks, the foundation slab was successfully applied by selecting correct raw materials, optimizing the proportions of concrete mix, using a reasonable concrete pouring process and strengthening the curing of concrete and testing the temperature of the concrete. It can provide reference for similar projects.

\section{The Engineering Situation}

The Holiday Hotel is located on the west side of Yanji South Street, the total construction area is $43112.21 \mathrm{~m}^{2}$, of which the underground is $6991 \mathrm{~m}^{2}$. The height of the building is $99.15 \mathrm{~m}$, there is 1 floor below the ground and 24 floors above the ground. (From the first to fifth floors are podium buildings). Foundation design of the main building and podium buildings in the project is a whole raft foundation, and set up cast belt. Because the average thickness of the foundation is $1.5 \mathrm{~m}$ and a large amount of one-time concrete pouring, this foundation project belongs to a mass concrete domain. The foundation concrete's strength grade is C40 and its impermeability grade is P6. In order to make full use of the later strength of concrete, the project uses the compressive strength of the concrete measured at 60 days as the concrete strength control index. 


\section{The Selection of Raw Materials and Mix Proportion Optimization Design}

The Selection of Raw Materials. The quality and economics of raw materials directly related to the quality of the concrete and the engineering cost. Yi Xing Commercial Concrete Company selects the raw materials locally according to the current situation of the building materials market of Yanji City and finally determines the following raw materials through comparative experiments.

Comment. Select Jilin Miao Ling 42.5 Portland cement with a low heat of hydration. So it can control the hydration heat release radically.

Flyash. Add some Class F Grade Two flyash to replace part of cement to reduce the heat of cement hydration heat, better the pump transportation behavior of concrete, improve the compactness of concrete and increase late strength of concrete.

Coarse aggregate and fine aggregate. Select the Medium sand produced in Yanji City whose modulus of fineness is 2.5 and the gradation is good as the fine aggregate. Select Continuous gradation rang from $5 \mathrm{~mm}$ to $25 \mathrm{~mm}$ stones also produced locally as the coarse aggregate. Because the Foundation engineering is constructed in summer, builders should put up a shed to store the aggregate to reduce the pouring temperature of concrete.

Pumping agent. Select naphthalene pumping agent with an excellent water reducing effect and slump-loss retarding, it also can better the concrete's pump transportation behavior.

Swelling agent. Select the swelling agent of UEA to compensate the shrinkage and creep, decrease the shrinkage stress of concrete caused by heat of hydration.

Water. Select clean and unpolluted groundwater.

The Mix Proportion Optimization Design. The project uses commercial concrete produced by Yi Xing Concrete Company. With the condition that the strength, working capability and durability of the concrete are well and take the reality that the strength of mass concrete in this project is $\mathrm{C} 40$ and the impermeability grade of it is P6 into account, the best mix proportion of mass concrete with C40 strength can be gained as shown in the Table 1. The thought to optimize the mix proportion of the mass concrete with $\mathrm{C} 40$ strength can be seen as the Fig. 1 shown. The parameters of mass concrete with C40 strength are following: the total amount of binder is $435 \mathrm{~kg} / \mathrm{m}^{3}$, the water-binder ratio is 0.39 , the substitution amount of coal ash for concrete is $15 \%$, the sand ratio is $49 \%$, the proportion of pumping aid is $2.18 \%$, the proportion of swelling agent is $5.75 \%$, the designed slumps is $180 \pm 30 \mathrm{~mm}$. After the adiabatic temperature rise experiments, the temperature control result and crack prevention of concrete are well.

The concrete samples are made according to the certain optimized mix proportion of mass concrete with $\mathrm{C} 40$ strength. And do compressive experiment on them to test compressive strength in the age of $3 \mathrm{~d}, 7 \mathrm{~d}, 28 \mathrm{~d}$ and $60 \mathrm{~d}$. The development laws of the concrete of the concrete would be shown in Fig. 2. The designed strength of concrete with C40 can be achieved in the age of $28 \mathrm{~d}$ and the configuration of concrete strength with $\mathrm{C} 40$ can be achieved in the age of $60 \mathrm{~d}$ which have met design requirements. After mixing the concrete, the slump of it is tested $185 \mathrm{~mm}$ and the water-retaining property and cohesive quality of it are well. Besides, the working capability of it is qualified.

Table 1. The C40 Mass Concrete Mix Design $\left(\mathrm{kg} / \mathrm{m}^{3}\right)$

\begin{tabular}{cccccccc}
\hline $\begin{array}{c}\text { Concrete } \\
\text { grade }\end{array}$ & Cement & Fly ash & Sand & Stone & Water & $\begin{array}{c}\text { Pumping } \\
\text { agent }\end{array}$ & $\begin{array}{c}\text { Swelling } \\
\text { agent }\end{array}$ \\
\hline C40 & 370 & 65 & 860 & 910 & 170 & 9.5 & 25 \\
\hline
\end{tabular}




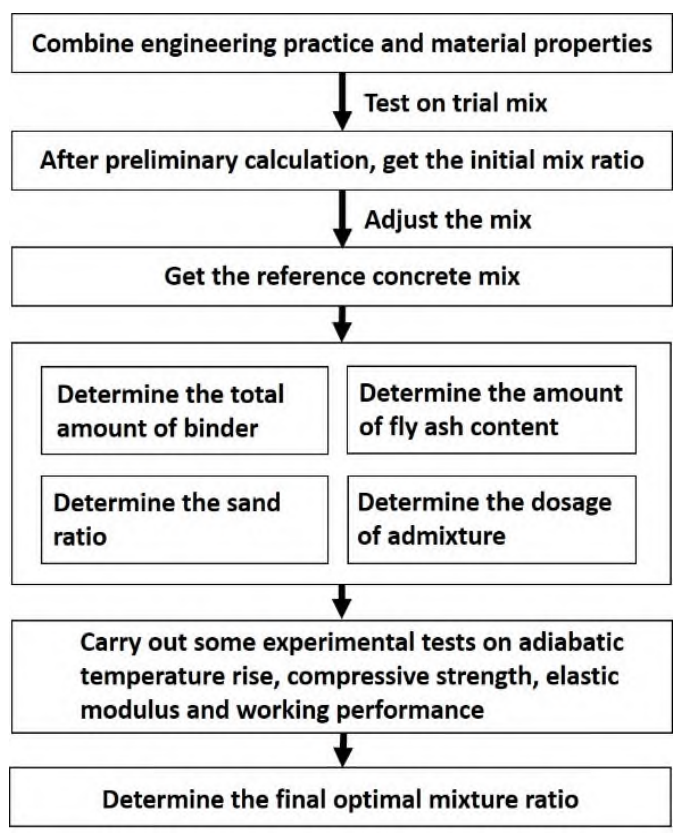

Fig. 1 The design of optimizing mix proportion.

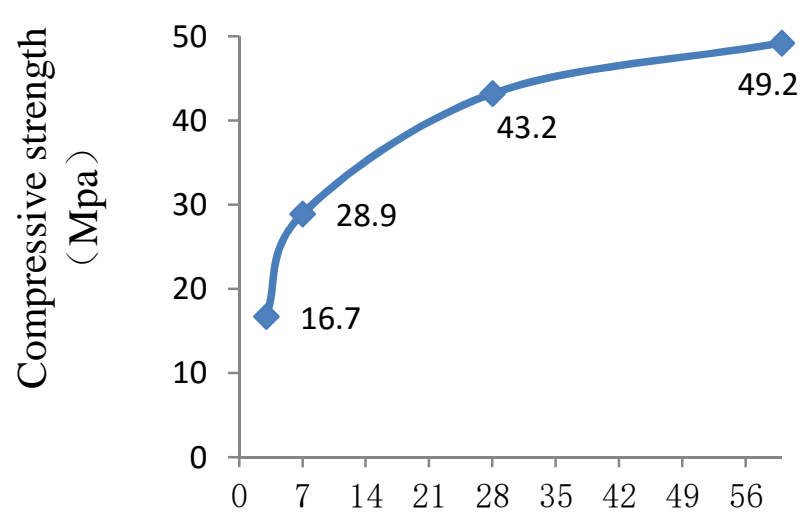

Concrete age(d)

Fig. 2 The Variation of compressive strength of concrete with age.

\section{The Innovative Technology of Concreting in Lifts, Vibrating Concrete and Surface Treatment}

The pouring of mass concrete is the key point in the whole construction process, and its key technologies include two parts, the pouring process and the temperature control in the pouring process [1]. Therefore, the project puts forward some innovative measures to strengthen the technology quality of the concrete pouring, vibration tamping, bleeding treatment and surface treatment to ensure the quality of construction of mass concrete.

Concreting in Lifts and Construction Technology. It has been proved by engineering practice that the pouring of mass concrete in lifts can reduce the temperature difference in the concrete structure, so as to effectively control the temperature crack [2]. The project adopts a layered pouring process which contains "a slope, oblique stratification, cycle to promote, once to the top". In other words, when the pumping concrete pouring, do the project in the slope of 1:6 first, the concrete is once poured to the top and forms a slope. Then pouring concrete layered along the slope, the concrete will flow forward and form as a fanat the same time. After that, pouring the concrete along the slope continuously, the thickness of the concrete poured each time is about $500 \mathrm{~mm}$. The thickness of the concrete floor in this project is $1.5 \mathrm{~m}$, and the process of pouringis achieved divided into three layers, the pouring process of the upper layermust be achieved before the lower concrete initialed. To avoid cracks, the slopes must be covered before pouring every time and specialists should be arranged to check. Pouring concrete forward according to the direction, and the elevation of the lower concrete must be achieved at the first pouring, thengo forward in order. The method of pouring mass concrete layered is shown in Fig. 3.

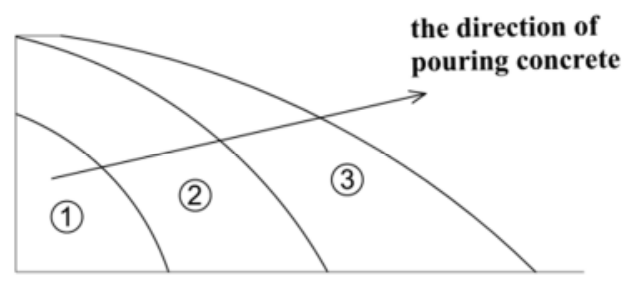

Fig. 3 The direction of pouring concrete. 
Concreting in Lifts and Construction Technology. Vibrating method and construction technology: A variety of engineering practices have proved that when the quality of vibrating is well protected, the concrete density will be higher, and the internal cracks in concrete will be decreased, the strength of the concrete will promote $10 \%-20 \%$ and the anti-cracking performance of concrete will be improved greatly [3]. The project adopts the mechanical vibrating with vibrating rod vibration, pay attention to twitch vibrating rod up and down when vibrating, and the distance is $50-100 \mathrm{~mm}$, vibrate each point last about 20 s to guarantee each point of upper, middle and lower of concrete vibrated evenly and densely. Two times vibration was adopted in this project to prevent the cracks and treat the common problem of concrete like bleeding and improve the compactness of the concrete.

Bleeding and Surface Treatment. The project of mass concrete is big fluidity of concrete, during the pouring and vibrating concrete will appear bleeding phenomenon actually. The water and mud bleeding upstream move forward along the concrete, along the slope flow to the bottom of the foundation. In the sump, engineer arranges some constructors to use small submersible pump to exclude the bleeding timely. Because of mass concrete in this project is commercial concrete, and its surface mortar is thick, after pouring the concrete within 3-4h (before concrete initial setting), the project needs surface treatment. Constructors use strike-off bar to do some scrape work after vibration. The second pressure needs to be done before the final condensate, reducing the surface cracks in mass concrete. The concrete should be covered by insulation film to prevent moisture to evaporate too quickly.

\section{Thermal Calculation and Maintenance Technology of Mass Concrete}

This project is combined with the calculation in Appendix B of Mass Concrete Construction Code of China (GB50496-2009), to determine the insulation measures to meet the maintenance conditions.

\section{The Calculation of Maximum Adiabatic Temperature Rise of Concrete.}

$$
T_{h}=m_{c} \cdot Q /(c \cdot \rho)
$$

In the formula, $T_{h}$ represents the maximum adiabatic temperature rise of concrete, $m_{c}$ represents cement dosage in concrete (including pumping agent). It can be shown $m_{c}=395 \mathrm{~kg} / \mathrm{m}^{3}$ from the mixture ratio. $Q$ represents the hydration heat of cementing materials, it can be calculated that $Q$ equals $358.135 \mathrm{~kJ} / \mathrm{kg}$, in which the hydration heat of cement $28 \mathrm{~d}$ is $375 \mathrm{~kJ} / \mathrm{kg}$. $C$ is the ratio of concrete heat capacity, $0.97 \mathrm{~kJ} /\left(\mathrm{kg}^{\circ} \mathrm{C}\right), \rho$ for concrete density, $2400 \mathrm{~kg} / \mathrm{m}^{3}$.

So the maximum adiabatic temperature rise of concrete can be calculated as $T_{h}=64.1^{\circ} \mathrm{C}$.

\section{The Calculation of Central Temperature.}

$$
T_{(1) t=} T_{a}+T_{h} \cdot X_{(t)}
$$

In the formula, $T_{1(t)}$ is the central temperature of concrete under the age of $t . T_{a}$ for concrete pouring temperature, take $25^{\circ} \mathrm{C} . X_{(t)}$ is the cooling coefficient at the age of $t$, according to the thickness of the plate $(3 \mathrm{~m})$ can be obtained $X_{(3)}=0.49$.

So the central temperature of concrete can be calculated as $T_{1(3)}=56.4^{\circ} \mathrm{C}$.

The Calculation of Concrete Surface Temperature.

$$
\begin{aligned}
& T_{b(t)}=T_{a}+4 h^{\prime}\left(H-h^{\prime}\right)\left[T_{l(t)}-T_{q}\right] / H^{2} \\
& h^{\prime}=k \cdot \lambda / \beta \\
& H=h+2 h^{\prime}
\end{aligned}
$$

In the formula, $T_{b(t)}$ is the surface temperature of concrete under the age of $t . \beta$ represents concrete pouring temperature. The insulation layer is made of a plastic film and a layer of $20 \mathrm{~mm}$ thick mats, therefore it can be calculated that $\beta=2.49$. $\lambda$ represents the coefficient of thermal conductivity of concrete, is $2.33 . \mathrm{k}$ represents the reduction factor, take $2 / 3$. $h$ 'represents concrete thickness of virtual, it is 0.624 in the project. $H$ is the computational thickness of concrete. $H$ equals 
2.758 in the project. The concrete surface temperature at the of $3 \mathrm{~d}$ is $\mathrm{T}_{b(3)}=46.9^{\circ} \mathrm{C}$.

Comprehensive the above results, it is shown that the temperature difference between inside and outside of the slab of mass concrete: $\mathrm{T}=56.4-46.9=9.5^{\circ} \mathrm{C}<25^{\circ} \mathrm{C}$, so there will be no concrete temperature crack.

The project takes some timely measures on heat insulation and wet keeping after the second plaster concrete curing. First, put a layer of insulation plastic film in the concrete surface. Then, lay a layer of $20 \mathrm{~mm}$ thick mat set according to the computation; At last, lay a layer of plastic film to reduce the temperature difference between inside and outside, prevent water loss. The curing of mass concrete motioned would be shown in Fig. 4.

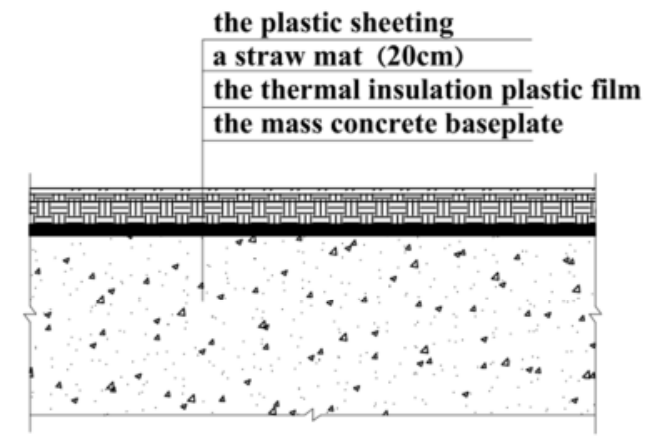

Fig. 4 The curing schematic diagram of mass concrete.

After conservation for about 14 days, the template is removed at a later date, and during which do regular watering on the insulation layer as moisturizing treatment to keep the concrete surface moist and prevent the concrete surface from shrinkage cracks. It is proved that the insulation measures which the project adopts, is useful to ensure the quality of mass concrete construction.

\section{Measures for Strengthening Mass Concrete Temperature Monitoring}

After pouring the mass concrete, keep up with the insulation and moisture curing measures in time, strengthen the temperature monitoring measures, and make the inside and outside differences in temperature controlled in $25^{\circ} \mathrm{C}$ or less and the cooling rate of concrete controlled in $2^{\circ} \mathrm{C}$ [4] or less to avoid producing temperature crack of concrete.

The JDC-2 type electronic thermometer is used in this project, by selecting the typical 10 groups of temperature measuring points, assign 3 middle and lower measuring points in every group of measuring points. There into, the higher and lower measuring points are $50 \mathrm{~mm}$ away from the surface, and the middle measuring point is the center of concrete. During the 1st day and 3rd day, measure it every 2 hours. During the 4th and 7th days, measure it every 4 hours. During the 8 th and 14th days, measure it every 12 hours. Manage the gathered temperature data in time, and take use of curve graph to reflect the inside and outside difference in temperature and cooling rate of the mass concrete. By the dynamic thermal insulation method of increasing or decreasing the thickness of insulation layer, both decrease the inside and outside difference in temperature of concrete and make the concrete have a good heat dispersion to ensure the mass concrete not to produce the temperature crack.

\section{Conclusion}

In HUAYI SHIHAO Hotel baseplate mass concrete construction process, construction units and Concrete Mixing Company worked together. They based principle on adopting the correct materials, they optimized concrete mix design and adopted innovative technology of concreting in lifts, vibrating concrete and surface treatment. They also kept up with the insulation and moisture curing measures in time. What they did had ensured the strength of concrete, durability and workability, avoided the occurrence of temperature cracks and ensured the quality of concrete. It has proved that 
this method was helpful to control temperature cracks of concrete which can provide references for similar projects.

\section{Acknowledgement}

In this paper, the research was sponsored by the Innovative Training Program for College Students of Yanbian University (Project No.ydbksky2016008).

\section{References}

[1] Z. F. Huang, H. L. Luo, Q. H. Zhang. The Pouring Construction of Mass Concrete. J. Guangxi University, 33(S1) (2008) 58-60.

[2] F. Xia. The Research about Temperature and Stress Field and Thermal Crack Control of Mass Concrete, Shenyang Architecture University, 2014.

[3] J. X. Zheng. Control of Cracks in Mass Concrete Construction of Super High-rise Buildings, Shanxi Architecture, 42(20) (2016) 83-85.

[4] F. G. Li, J. L. Wei. Construction technology and quality Control of Super High-rise Building, Constr. Tech. 44(21) (2015) 130-134. 